Volodymyr Atamanyuk and Yaroslav Gumnytskyi

\title{
MASS EXCHANGE DYNAMICS DURING THE SECOND FILTRATION DRYING PERIOD
}

\author{
Lviv Polytechnic National University, 12 Bandera str., 79013 Lviv, Ukraine \\ Atamanyuk@ukr.net, Jgumnycky@ukr.net
}

Received: J anuary 21, 2009

(C) Atamanyuk V., Gumnytskyi Y. 2009

\begin{abstract}
The work is dedicated to theoretical and experimental investigations of kinetics and dynamics of filtration drying of capillary and pore materials, and mineral granulated fertilizers, in particular. The proposed physical model of a moist particle and the differential system of equations which describes heat exchange in the second drying period enables to determine the transfer velocity of mass-exchange zone in a dispersion layer of the material during filtration drying.
\end{abstract}

Key words: kinetics, dynamics, filtration drying, dispersion material, fertilizers, second period, mathematical model, physical model.

\section{Introduction}

The nature of filtration drying consists of heat agent filtration through the pore structure of dispersion material layer [1]. Thus the heat agent washes every layer particle and the drying of a layer can be considered as the drying of separated particles. There are three possible cases during filtration drying of dispersion material. The particles of the layer contain only the outer moisture (sand after enrichment process) which must be removed, only the inner moisture (mineral fertilizers, technical carbon after granulation process) or the outer and inner moisture (coal after enrichment processes). Thus the drying of separate particles can be only in the first period or only in the second one or both in the first and the second ones.

During filtration drying of dispersion material the moisture content is changed due to time and height of the layer. The reason of moisture content change due to height is a change of moisture content of separate particles which form the layer. That is the moisture content of dispersion layer is a function of three variables:

$$
w^{c}=f(r, h, \tau)
$$

It is known that to force out the inner moisture from pores and capillaries is harder than moisture which is on the surface of the particles. Moreover, it is necessary to determine complicated composition of moist capillary porous particles concerning values of heat conductivity coefficients because a particle consists of a solid phase (skeleton of solid particle), a liquid phase (water) and a gas phase (air and water steam). Each of these three components has its own heat conductivity coefficient. In the heat transmission process only the solid phase preserves its composition. The amount of liquid phase decreases and amount of gas-vapor mixture increases in the drying process. Therefore, filtration drying of dispersive capillary porous materials is complicated heat- and mass transfer process taking place with a mass transfer moving boundary. At first the layer of dispersive material, which contacts with a heat agent, is dried and then the masstransfer boundary moves toward the lower layers along the movement of the heat agent. That is why this work is dedicated to experimental and theoretical investigations of forcing out the moisture during filtration drying of granulated mineral fertilizers.

\section{Experimental}

The experimental investigations were made on the equipment and by the method described in [2]. The mineral fertilizers are chosen for investigation of filtration drying ammophos $\left(\mathrm{NH}_{4} \mathrm{H}_{2} \mathrm{PO}_{4}\right)$ and double superphosphate $\mathrm{Ca}\left(\mathrm{H}_{2} \mathrm{PO}_{4}\right)_{2}$. The process of filtration drying proceeds at heat agent temperature $323 \mathrm{~K}$, and fictitious velocity of the heat agent $v_{0}=1.26 \mathrm{~m} / \mathrm{s}$ for ammophos and $v_{0}=1.28 \mathrm{~m} / \mathrm{s}$ for superphosphate .

The granulated ammophos is a polydispersive mixture of rounded granules from 1 to $5 \mathrm{~mm}$. The bulk weight $\rho_{\mathrm{b}}=900 \mathrm{~kg} / \mathrm{m}^{3}$. Porosity of the layer is $\varepsilon_{\text {out }}=0.393 \mathrm{~m}^{3} / \mathrm{m}^{3}$ and inner porosity of grains $\varepsilon_{\text {inn }}=0.136 \mathrm{~m}^{3} / \mathrm{m}^{3}$. The granulated double super phosphate is a poly dispersion mixture of rounded granules from 1 to $4 \mathrm{~mm}$. The bulk weight $\rho_{\mathrm{b}}=860 \mathrm{~kg} / \mathrm{m}^{3}$. Porosity of layer is $\varepsilon_{\text {out }}=0.386 \mathrm{~m}^{3} / \mathrm{m}^{3}$, and inner porosity of grains - 
$W^{c}, \mathrm{~kg} \mathrm{H}_{2} \mathrm{O} / \mathrm{kg}$ of dry material

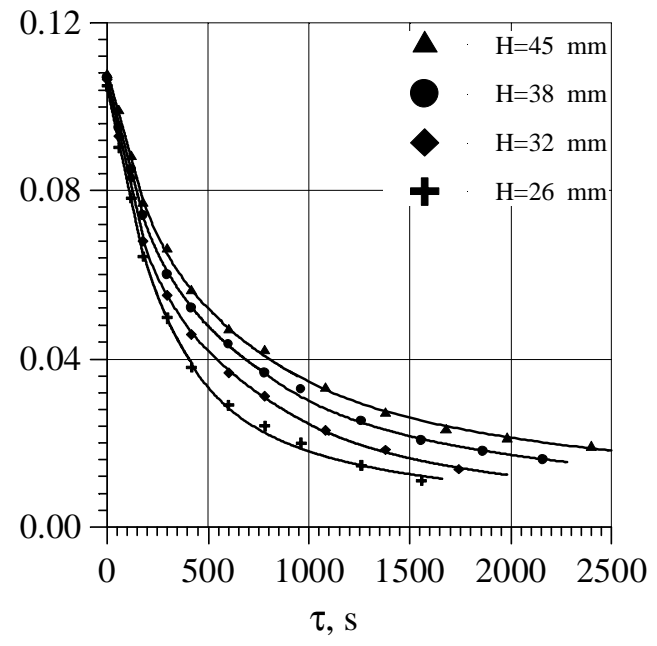

a
$W^{c}, \mathrm{~kg} \mathrm{H} 2 \mathrm{O} / \mathrm{kg}$ of dry material

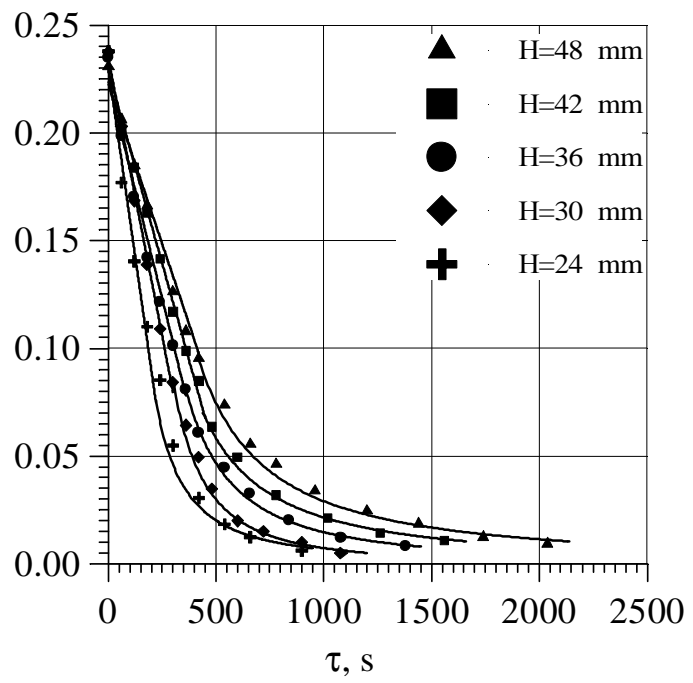

b

Fig. 1. Moisture content change during filtration drying $(\mathrm{T}=323 \mathrm{~K})$ of granulated ammophos with $u_{0}=1.26 \mathrm{~m} / \mathrm{s}$ (a) and granulated double superphosphate with $u_{0}=1.28 \mathrm{~m} / \mathrm{s}(\mathrm{b})$

$\varepsilon_{i n n}=0.244 \mathrm{~m}^{3} / \mathrm{m}^{3}$. The granulating technology $[3,4]$ provides the homogeneous distribution of moisture in a granule volume, and moreover, the moisture on the surface of granules is absent. The initial moisture content of granulated fertilizers determines the dispersion of the produced material and certainly, the porosity of received granules.

\section{Results and Discussion}

\subsection{Experimental Investigations}

The kinetics of ammophos filtration drying and double super phosphate after the granulating process is shown in Fig 1.

During drying of granulated fertilizers the inner moisture has to be forced out from pores and capillaries of granules. The drying investigations of separate particles of considered mineral fertilizers clearly point to the absence of the surface moisture; the inner moisture must be forced out. This process is limited by outer diffusion laws, and its velocity decreases in time due to the particle drying. In the literature this process is considered to be named as the second drying period [5], unlike the first one, where the moisture forcing out from the material surface is taking place with a constant velocity.

The analysis of curves in Fig. 1 shows that the drying of mineral fertilizers in the stationary layer is accompanied by the constant velocity (straight forward curve parts at the initial time period), though the drying of separate particles exceptionally takes place in the second period. This paradox seems to be explained by the phenomenon, that the drying agent filtered through the stationary layer is saturated by the water steam on the height which is less then the height of moisture material. The transport of the moisture content front in the direction of the heat agent to the perforated partition is characterized by the constant drying velocity. After reaching the perforated partition the mass exchange area decreases and the moisture quantity decreases respectively that is evaporated during the time unit and therefore, we have the second period on the kinetic curves of drying. That is, the first period does not mean the free moisture forcing out during filtration drying, and the second period of the bound one. It points to the difference between the filtration drying and the connective one.

In order to confirm the above-mentioned, we give the dependence of drying velocity on the layer moisture content (Fig. 2). We see that the drying velocity in the first period ("b - c" lines) depends on the layer height of dispersion material, and because of the layer, height growth the drying velocity decreases, but it is not observed during convective, conductive and other drying methods. This divergence can be explained by the fact that during filtration drying the heat exchange area moves in the direction of heat agent to perforated partition. The transport velocity of heat exchange area for concrete dispersion material depends on drying potential of the heat agent. Therefore, the achievement time of perforated partition at similar transport velocity of the heat exchange area for different layer height of dispersion material will be various. This is observed on kinetic curves in Fig. 1 and lines " $b-c$ " of Fig. 2. Since the achievement by forehead part of the mass exchange area of perforated partition the drying velocity decreases to the achievement of equilibrium moisture and we have the second period in Fig. 1 (Fig. 2, lines "c - d") on the drying curves. 


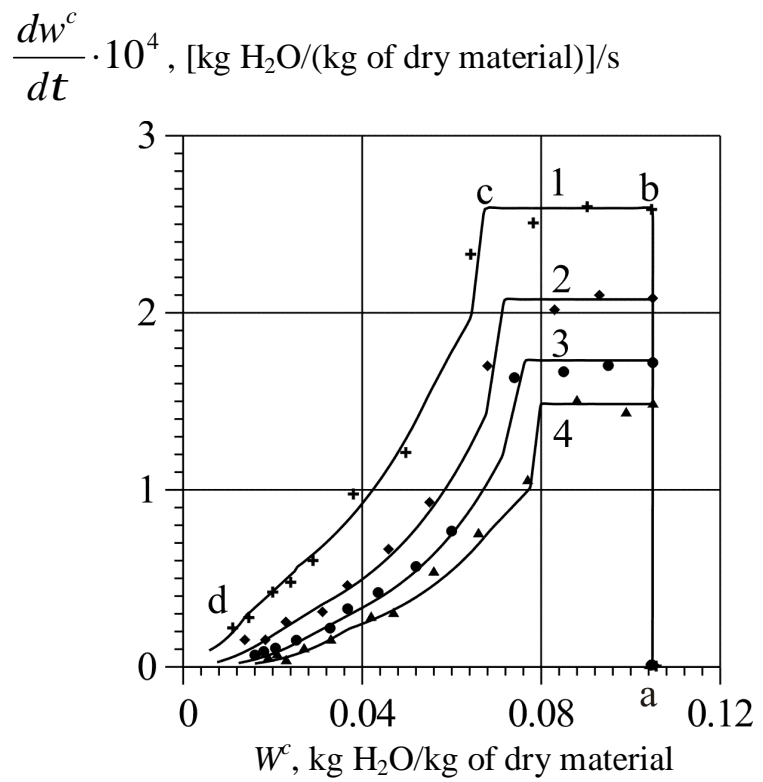

a $\frac{d w^{c}}{d \tau} \cdot 10^{4},\left[\mathrm{~kg} \mathrm{H} \mathrm{H}_{2} \mathrm{O} /(\mathrm{kg}\right.$ of dry material $\left.)\right] / \mathrm{s}$

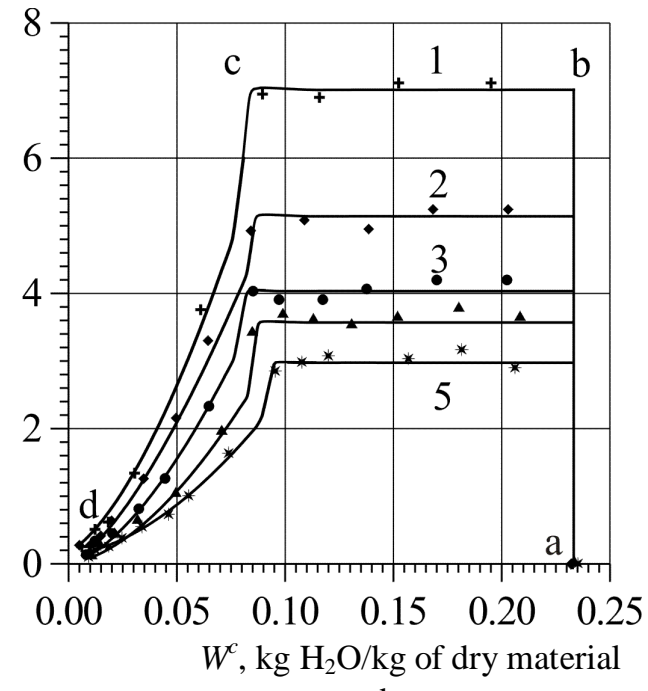

b

Fig. 2. The change of drying velocity vs layer moisture content: ammophos (a) and superphosphate (b) (marks according to Fig. 1)

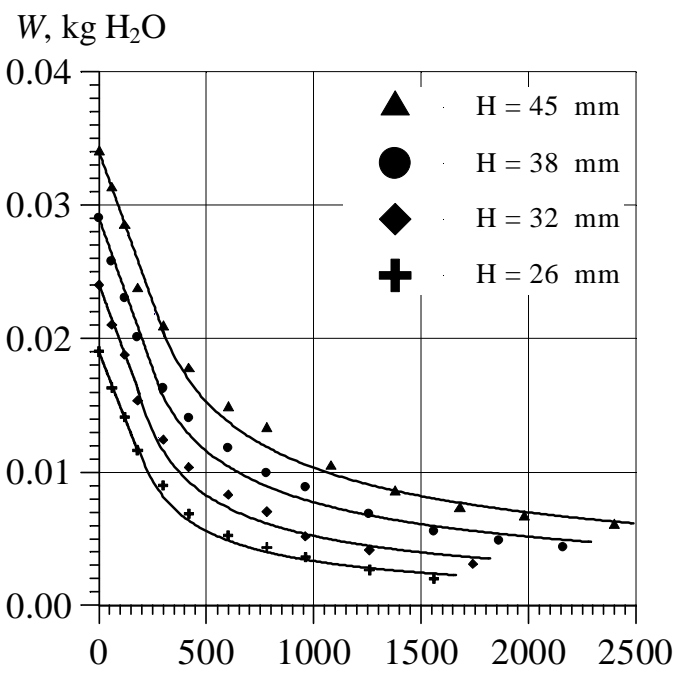

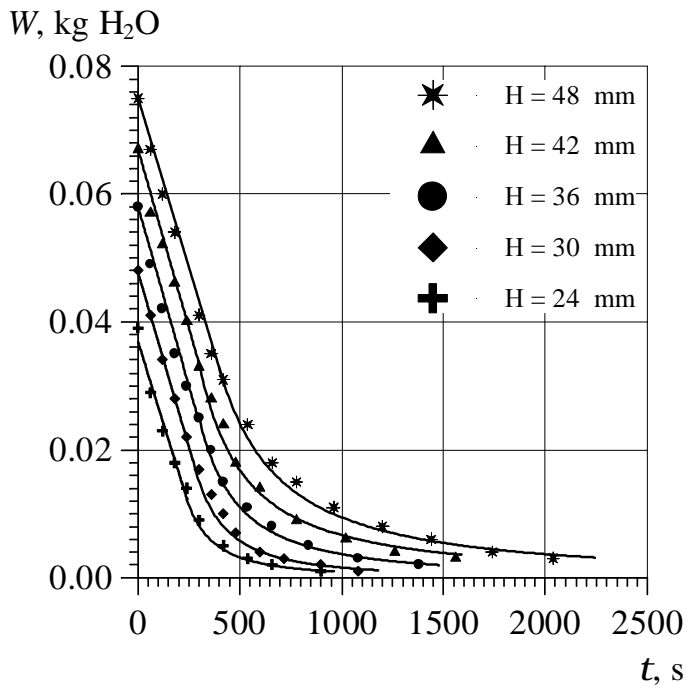

b

Fig. 3. The change of moisture quantity in the layer during filtration drying: ammophos (a) and superphosphate (b)

In order to confirm the aforesaid, the dependence of the quality change of moisture in the layer of mineral fertilizers during filtration drying is shown in Fig. 3. The analysis of Fig. 3 shows, that the moisture quantity in the layer increases at the height growth, but the forcing out intensity is similar for all heights; it confirms the parallelism of curves between themselves.

The velocity of moisture forcing out from the layer is shown in Fig. 4. We see that the velocity of forcing out moisture does not depend on the layer thickness, and analogously, as for convective drying depends only on drying potential of the heat agent in the first period and on the material structure and binding form of moisture with a hard skeleton of moisture material in the second period.

The analysis of above-mentioned results enables to infer the following conclusions:

1. The kinetic curves of drying does not show the physical nature of the process, because there are simultaneously dry and moisture materials in the layer and the bigger is the layer height, the more real moisture of 
$\frac{d W}{d \tau}, \mathrm{kg} \mathrm{H}_{2} \mathrm{O} / \mathrm{s}$

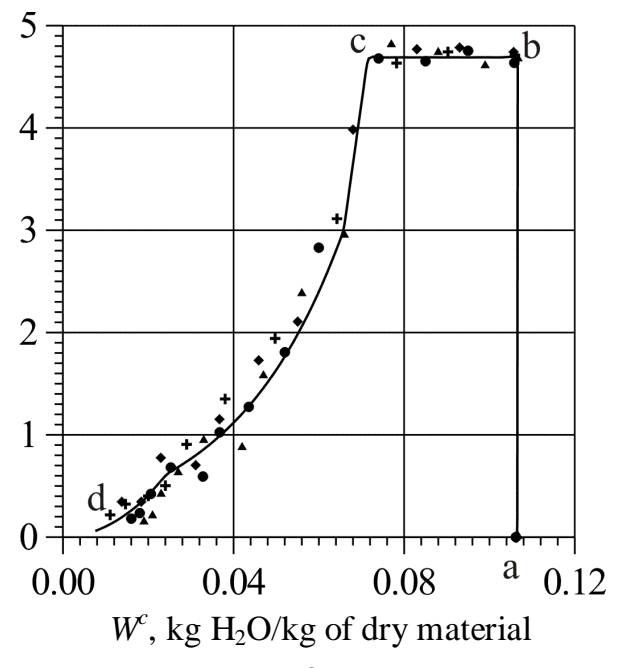

$\frac{d W}{d \tau}, \mathrm{kg} \mathrm{H}_{2} \mathrm{O} / \mathrm{s}$

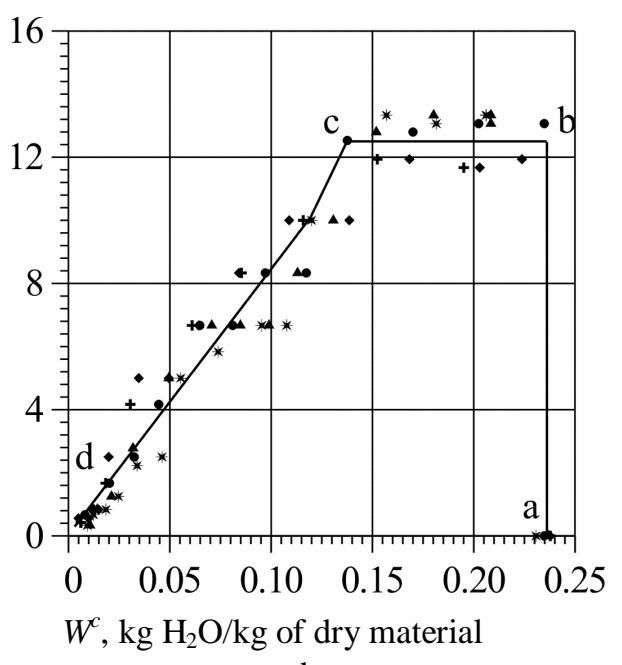

b

Fig. 4. The change of moisture removal velocity from the layer during filtration drying $v s$ its moisture content: ammophos (a) and superphosphate (b)

lower layers during the drying process differs from the middle one in the kinetic drying curve.

2. The process of filtration drying can be described more adequately on the basis of forcing out moisture dynamics from the layer.

Therefore, it is worth using the dynamics of moisture removal process from solid particles and the dynamics of moisture content change of the heat agent for mathematical description of filtration drying of dispersion materials.

\subsection{Theoretical Part}

The dynamics of the drying process considers the changes of the heat agent moisture content and the material to be dried in the layer of the dispersion material, in this case during the second period of filtration drying. It is accepted that particles have a spherical form, they are monodispersed and their kinetic parameters are isotropic. At the initial moment of time the moisture content of all particles is similar and equals to $w_{n}^{c}$. During drying the moisture content of particles changes to the equilibrium value $w_{p}^{c}$ (Fig. 5). The heat agent is supplied for drying with the initial moisture $x_{1}=x_{n}$. In the process of its filtration through the grained material its moisture content increases to $x_{1}=x_{k}$ (Fig. 6).

During consideration of the mathematical model only the diffusion motion of water steam inside pores and capillaries is taken into account. Having considered our investigations [6] from the heating process of a solid particle, it is fixed that the process of heat exchange takes place more rapidly then that of mass exchange, and therefore, we accept the average meaning of the inner diffusion coefficient of water vapours at the maximal heating temperature of the particle. This phenomenon has been fixed by other investigators, too [7].

The forming of the mathematical model foresees the layer-to-layer forcing out of the moisture from the solid particle, forming of evaporation front and its dislocation in the depth of the particle. The particle with a spherical form and R-radius with existed pores is shown in Fig. 7 (only several ones are shown as an example).

This scheme shows the state of the material during the second period at an arbitrary time moment $\tau$. The moisture in the condensation state is on the radius $r_{0}$ which is a distribution boundary of two phases. The steam in the saturation state with $x_{\text {sat }}$ moisture content is over the surface of the liquid. On the current radius $r$ the moisture content will have $x$ value. On the surface of the particle the moisture content values correspond to $x(R)=x_{1}$ meanings in the heat agent. During drying process the division boundary moves in depth of the particle, and its average moisture content decreases. The proposed model is similar to the extraction process from the solid phase of hard inclusions which fill monolithically the pores of inert materials [8], but the process of the inner diffusion transfer during filtration drying is more complicated, because in our situation besides the change of moisture quantity in pores the temperature of the hard particle is changing, too. The complexity of the mathematical model also consists in the reason that the scheme with movable boundaries of phases is considered and it makes the analytical solution more complicated.

The correlation between the dimensionless radius of the evaporation front $\varphi_{0}$ and moisture content of the particle is calculated by the dependence: 


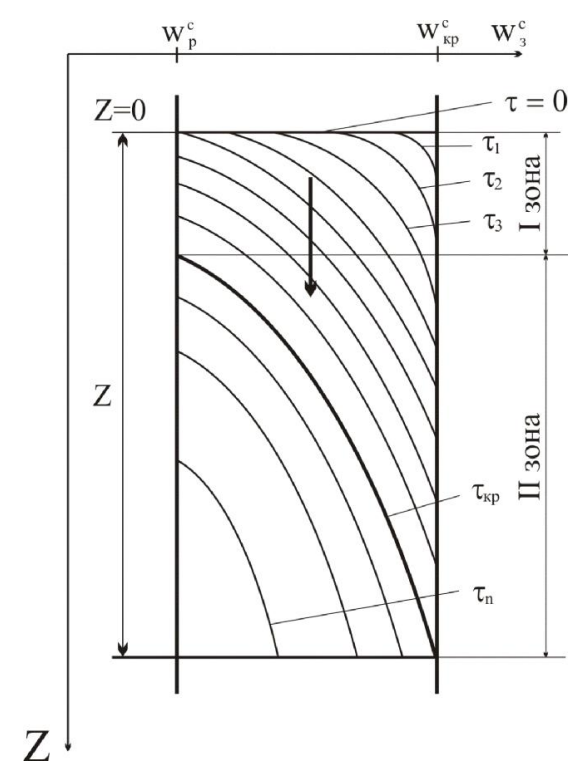

Fig. 5. Calculation scheme of moisture content change vs time and height of layer: dry material zone (I) and moisture material zone (II)

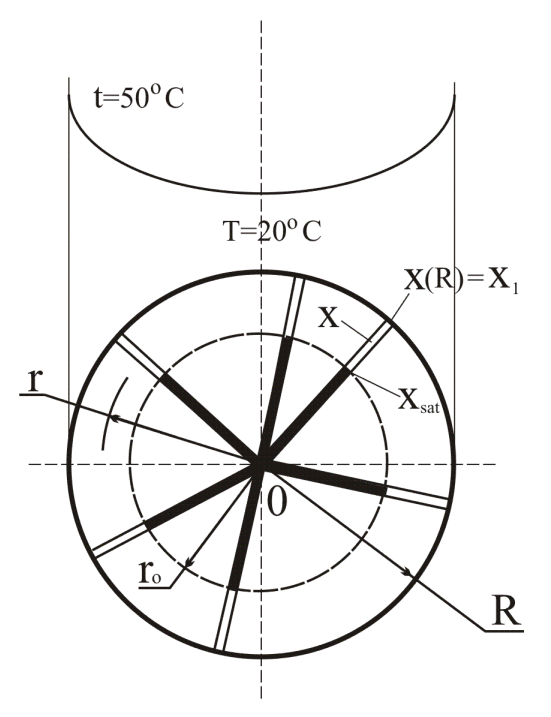

Fig. 7. Scheme of moisture and temperature distribution inside the solid particle during the second period of drying at time moment $t$

$$
\varphi_{0}=\sqrt[3]{\frac{w^{c}}{w_{2}^{c}}}
$$

$$
w_{2}=w_{k p} \text {, if } w_{0} \geq w_{k p}, w_{2}=w_{0} \text {, if } w_{0}<w_{k p} \text {. }
$$

The task of drying dynamics in a layer of grained material foresees the determination of a temperature field as a function of coordinates and time. Using the dimensionless layer height of $\omega$ and dimensionless time

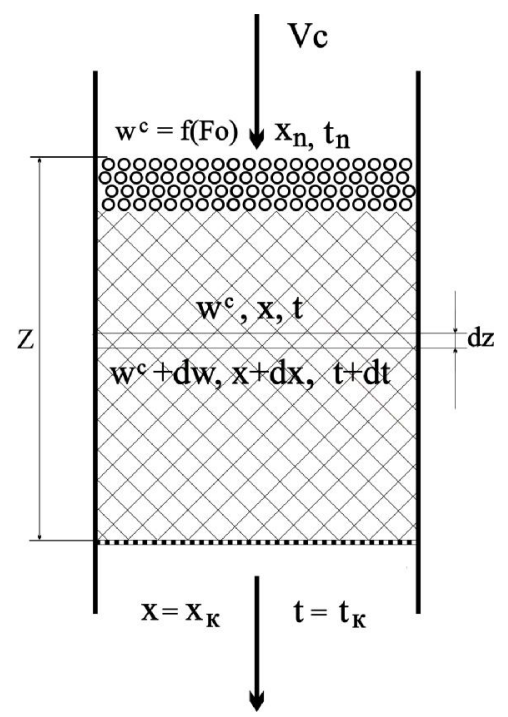

Fig. 6. Distribution of temperatures, moisture content of particles in dispersion material and heat agent during filtration drying in the second period

of $F o_{\mathrm{d}}$, the temperature field will be the function of these parameters.

$$
x_{1}=f\left(\omega, F o_{\mathrm{d}}\right) ; \varphi_{0}=f\left(\omega, F o_{\mathrm{d}}\right)
$$

Let us formulate the mathematical model of the process in the form of differential equations:

$$
\begin{gathered}
-\frac{\partial}{\partial \tau}\left(\frac{4}{3} \cdot \pi \cdot r_{0}^{3} \cdot \varepsilon_{i n n} \cdot \rho_{s}\right)= \\
=-D_{w} \cdot 4 \cdot \pi \cdot R^{2} \cdot \varepsilon_{i n n} \cdot\left(\frac{\partial x_{2}}{\partial \tau}\right)_{r=R} \cdot \rho \\
D_{w} \cdot\left(\frac{\partial x_{2}}{\partial r}\right)_{r=R} \cdot \rho=\beta \cdot\left(x_{2 n}-x_{1}\right) \cdot \rho \\
v \cdot\left(\frac{\partial x_{1}}{\partial z}\right)^{\prime} \rho=-\frac{\rho_{s a t}}{\rho_{s} \cdot \frac{4}{3} \cdot \pi \cdot R^{3}} \cdot D_{w} \cdot 4 \cdot \pi \\
\cdot R^{2} \cdot \varepsilon_{i n n} \cdot\left(\frac{\partial x_{2}}{\partial r}\right)_{r=R} \cdot \rho
\end{gathered}
$$

Eq. (3) is a kinetic equation and shows the transport velocity of the evaporation front inside the particle. Eq. (4) defines the boundary condition of the third kind at the boundary "solid - heat agent". The third equation describes the moisture content changes of the heat agent according to the layer height of dispersion material. 
Let us complete Eqs. (3)-(5) by initial conditions:

$$
x_{1}\left(0, F O_{\mathrm{d}}\right)=x_{n} ; \varphi(\omega, 0)=1
$$

The concentration distribution of moisture in a solid particle at $r_{0}-R$ interval is shown by the differential equation of the molecular diffusion. Including sluggishness of the second stage we will accept quasi-stationary conditions and the differential equation of molecular diffusion for particles with a spherical form will be as follows:

$$
\frac{\partial^{2} x_{2}}{\partial r^{2}}+\frac{2}{r} \cdot \frac{\partial x_{2}}{\partial r}=0
$$

Having integrated this equation in the limits $r=r_{0}$ $x_{2}=x_{\text {sat }}$ and $r=R \quad x_{2}=x_{2 n}$ we will have the results:

$$
\frac{x_{s a t}-x_{2}}{x_{s a t}-x_{2 n}}=\frac{1-\frac{\varphi_{0}}{\varphi}}{1-\varphi_{0}}
$$

where $\varphi=\frac{r}{R} ; \varphi_{0}=\frac{r_{0}}{R}$.

Having introduced dimensionless parameters in solving task we received:

$$
\omega_{d}=\frac{\rho_{s a t} \cdot D_{w} \cdot \varepsilon_{i n n} \cdot z}{\rho_{s} \cdot R^{2} \cdot v}-\text { dimensionless layer }
$$

length during the mass exchange process;

$$
\begin{aligned}
& F o_{\mathrm{d}}=\frac{D_{w} \cdot \tau}{R^{2}}-\text { diffusion Furie's number; } \\
& B i_{\mathrm{d}}=\frac{\beta \cdot R}{D_{w}}-\text { diffusion Bio's number; } \\
& \Delta \rho=\frac{\rho_{\mathrm{H}_{2} \mathrm{O}}}{\rho}-\text { relative density }
\end{aligned}
$$

The system (3) - (5) in dimensionless parameters will be as follows:

$$
\begin{gathered}
\Delta \rho \cdot \varphi_{0}^{2} \cdot \frac{\partial \varphi_{0}}{\partial F o_{d}}=\left(\frac{\partial x_{2}}{\partial \varphi}\right)_{\varphi=1} \\
-\left(\frac{\partial x_{2}}{\partial \varphi}\right)_{\varphi=1}=B i_{d} \cdot\left(x_{2 n}-x_{1}\right) \\
\frac{\partial x_{1}}{\partial \omega_{d}}=-3 \cdot\left(\frac{\partial x_{2}}{\partial \varphi}\right)_{\varphi=1}
\end{gathered}
$$

Having differentiated the Eq. (8) at $\partial \varphi$ we will get:

$$
-\frac{\partial x_{2}}{\partial \varphi}=\frac{x_{\mathrm{sat}}-x_{2 n}}{1-\varphi_{0}} \cdot \frac{\varphi_{0}}{\varphi^{2}}
$$

For conditions on the limit $(\varphi=1)$ we get:

$$
\left(\frac{\partial x_{2}}{\partial \varphi}\right)_{\varphi=1}=-\left(x_{s a t}-x_{2 n}\right) \cdot \frac{\varphi_{0}}{1-\varphi_{0}}
$$

Substituting (9) in Eq. (11) we get:

$$
\frac{\partial x_{1}}{\partial \omega_{d}}+3 \cdot \Delta \rho \cdot \varphi_{0}^{2} \cdot \frac{\partial \varphi_{0}}{\partial F o_{\text {д }}}=0
$$

Using dependence (12), Eq. (9) will be as follows:

$$
\Delta \rho \cdot \varphi_{0} \cdot\left(1-\varphi_{0}\right) \cdot \frac{\partial \varphi_{0}}{\partial F o_{\mathrm{d}}}=-x_{s a t}+x_{2 n}
$$

Let us exclude from the dependence (14) the moisture content on the surface of $x_{2 n}$.particle. For this purpose we use the limit condition (10). It enables to find equation for determination of moisture content of the heat agent $x_{1}$ : $x_{1}=x_{s a t}+\Delta \rho \cdot \varphi_{0} \cdot\left(1-\varphi_{0}\right) \cdot \frac{\partial \varphi_{0}}{\partial F o_{\mathrm{d}}}+\frac{1}{B i_{\mathrm{d}}} \cdot \Delta \rho \cdot \varphi_{0}^{2} \cdot \frac{\partial \varphi_{0}}{\partial F o_{\mathrm{d}}}$

We find the partial solution for the initial crosssection $\varphi_{0}\left(0, F o_{\mathrm{d}}\right)$. For these conditions the moisture content value stays non-variable and equals to $x_{1}=x_{n}$.

We integrate Eq. (15) in the limits $F o_{\mathrm{d}}=0-$ $\varphi_{0}=1 ; F o_{\mathrm{d}}-\varphi_{0}$ by division of variables.

$$
-\int_{1}^{\varphi_{0}} \varphi_{0} \cdot\left[\frac{\varphi_{0}}{B i_{\mathrm{d}}}+\left(1-\varphi_{0}\right)\right] \cdot \partial \varphi_{0}=\frac{x_{s a t}-x_{n}}{\Delta \rho} \cdot \int_{0}^{F o_{\mathrm{d}}} \partial F o_{\mathrm{d}}
$$

The solution of this equation enables to determine the change of moisture content in the surface layer of the grained material according to time:

$$
\frac{1}{6}-\frac{\varphi_{0}^{2}}{2}+\frac{\varphi_{0}^{3}}{3}+\frac{1}{3 \cdot B i_{\mathrm{d}}} \cdot\left(1-\varphi_{0}^{3}\right)=\frac{x_{s a t}-x_{n}}{\Delta \rho} \cdot F o_{\mathrm{d}}
$$

or including (1)

$$
\frac{1}{6}-\frac{1}{2} \cdot\left(\frac{w^{c}}{w_{2}^{c}}\right)^{2 / 3}+\frac{1}{3} \cdot \frac{w^{c}}{w_{2}^{c}}+\frac{1}{3 \cdot B i_{\mathrm{d}}} \cdot\left(1-\frac{w^{c}}{w_{2}^{c}}\right)=\frac{x_{s a t}-x_{n}}{\Delta \rho} \cdot F O_{\mathrm{d}}
$$

Let us determine the drying time of the surface layer in the grained material $\left(w^{c}=w_{p}^{c}\right)$. This responds to the value $w_{2}^{c}=w_{p}^{c}$, a $\varphi_{0}=0$. It means that there is not 
condensated moisture in the particle, the pores are filled with vapour and gas mixture which is in equilibrium with the heat agent. Let us mark this time as $F o_{d}=F o_{d 0}$.

$$
F o_{\mathrm{d} 0}=\frac{\Delta \rho}{x_{\text {sat }}-x_{n}} \cdot\left(\frac{1}{6}+\frac{1}{3 \cdot B i_{\mathrm{d}}}\right)
$$

Later the layer of particles which will be dried at the second period to the equilibrium state, will increase and move down until it reaches the perforated partition where the dispersion material is located. At $F o_{\mathrm{d}}>F o_{0 \mathrm{~d}}$ values two zones are formed. In the first zone the moisture content of solid particles has equilibrium value with moisture content of the heat agent, and at this height the value $\varphi_{0}=0$. Drying of hard particles at the second period is taking place, in time this zone will diminish. Therefore, this task belongs to the tasks with a movable limit (boundary) that separates the dried zone from the zone of drying.

Let us use Eqs. (11) and (15) for solution of this task. It is possible to define from Eq. (11) the change of moisture content of the heat agent according to the layer height $\frac{\partial x_{1}}{\partial \omega_{d}}$, and Eq. (15) will be as follows:

$$
x_{1}=x_{s a t}+\Delta \rho \cdot \frac{\partial}{\partial \mathrm{Fo}_{\mathrm{d}}}\left[\frac{\varphi_{0}^{3}}{3} \cdot\left(\frac{1}{B i_{\mathrm{d}}}-1\right)+\frac{\varphi_{0}^{2}}{2}\right]
$$

Then the value $\frac{\partial x_{1}}{\partial \omega_{d}}$ will be equal to:

$$
\frac{\partial x_{1}}{\partial \omega_{d}}=\Delta \rho \cdot \frac{\partial^{2}}{\partial \omega_{d} \cdot \partial \mathrm{Fo}_{\mathrm{d}}}\left[\frac{\varphi_{0}^{3}}{3} \cdot\left(\frac{1}{B i_{\mathrm{d}}}-1\right)+\frac{\varphi_{0}^{2}}{2}\right]
$$

Having substituted the received value $\frac{\partial x_{1}}{\partial \omega_{d}}$ and $\left(\frac{\partial x_{2}}{\partial \varphi}\right)_{\varphi=1}$ from Eq. (9) and in Eq. (11), and in result this equation will have the following form:

$$
\frac{\partial^{2}}{\partial \omega_{d} \cdot \partial F o_{\mathrm{d}}}\left[\frac{\varphi_{0}^{3}}{3} \cdot\left(\frac{1}{B i_{\mathrm{d}}}-1\right)+\frac{\varphi_{0}^{2}}{2}\right]=-3 \cdot \varphi_{0}^{2} \cdot \frac{\partial \varphi_{0}^{2}}{\partial F o_{\mathrm{d}}}
$$

Let us integrate the above-written equation by dimensionless $\mathrm{Fo}_{\mathrm{d}}$ time:

$$
\frac{\partial^{2}}{\partial \omega_{d}} \cdot\left[\frac{\varphi_{0}^{3}}{3}\left(\frac{1}{B i_{\mathrm{d}}}-1\right)+\frac{\varphi_{0}^{2}}{2}\right]=-\varphi_{0}^{3}+c
$$

We define the integration constant "c" from initial conditions. When $F o_{\partial}=0 ; \varphi_{0}=1$, and $\frac{\partial \varphi_{0}}{\partial \omega_{\partial}}=0$; then $c=\varphi_{0}^{3}=1$. taking into account the integration constant Eq. (21) will have the following form:

$$
\left[\varphi_{0}^{3} \cdot\left(\frac{1}{B i_{\partial}}-1\right)+\varphi_{0}\right] \frac{d \varphi_{0}}{d \omega_{\partial}}=1-\varphi_{0}^{3}
$$

We solve this solution by the method of constants dividing in the limits of $\omega_{d}=0-\varphi_{0}\left(0, F o_{\mathrm{d}}\right)$; $\omega_{d}=\omega_{d}-\varphi_{0}\left(\omega_{d}, F o_{\mathrm{d}}\right)$

$$
\begin{gathered}
\int_{\varphi_{0}\left(0 ; F_{O_{\mathrm{d}}}\right)}^{\varphi_{0}\left(\omega_{d}, F o_{\mathrm{d}}\right)} \frac{\varphi_{0}^{2}}{1-\varphi_{0}^{3}} \cdot\left(\frac{1}{B i_{d}}-1\right) d \varphi_{0}+ \\
+\int_{\varphi_{0}\left(0 ; F_{o_{\mathrm{d}}}\right)}^{\varphi_{0}\left(\omega_{d}, F_{o_{d}}\right)} \frac{\varphi_{0} \cdot d \varphi_{0}}{1-\varphi_{0}^{3}}=\int_{0}^{\omega_{d}} d \omega_{d}
\end{gathered}
$$

Integrating of the left part of Eq. (23) is a tabular one [9] and can be represented in the form:

$$
\begin{gathered}
\int_{\varphi_{0}\left(0 ; F \sigma_{\mathrm{d}}\right)}^{\varphi_{0}\left(\omega_{d} F \sigma_{\mathrm{d}}\right)} \frac{\varphi_{0}^{2} d \varphi_{0}}{1-\varphi_{0}^{3}}=-\frac{1}{3} \cdot \ln \left(1-\varphi_{0}^{3}\right) \\
\int_{\varphi_{0}\left(0 ; F \sigma_{\mathrm{d}}\right)} \frac{\varphi_{0} d \varphi_{0}}{1-\varphi_{0}^{3}}=\frac{1}{6} \cdot \ln \cdot \frac{1+\varphi_{0}+\varphi_{0}^{2}}{\left(1-\varphi_{0}\right)^{2}}-\frac{1}{\sqrt{3}} \operatorname{arctg} \frac{2 \cdot \varphi_{0}}{\sqrt{3}}
\end{gathered}
$$

The solution of differential Eq. (23) in general form can be represented by the following dependence:

$$
\Phi\left[\varphi_{0}\left(\omega_{d}, F o_{\mathrm{d}}\right)\right]-\Phi\left[\varphi_{0}\left(0, F o_{\mathrm{d}}\right)\right]=\omega_{d}
$$

where

$$
\begin{gathered}
\Phi\left[\varphi_{0}\left(\omega_{d}, F o_{\mathrm{d}}\right)\right]=\left(1-\frac{1}{B i_{d}}\right) \cdot \frac{1}{3} \cdot \ln \left[1-\varphi_{0}^{3}\left(\omega_{d}, F o_{\mathrm{d}}\right)\right]- \\
-\frac{1}{\sqrt{3}} \cdot \operatorname{arctg} \frac{2 \cdot \varphi_{0}\left(\omega_{d}, F o_{\mathrm{d}}\right)+1}{\sqrt{3}}+ \\
+\frac{1}{6} \cdot \ln \frac{1+\varphi_{0} \cdot\left(\omega_{d}, F o_{\mathrm{d}}\right)+\varphi_{0}^{2}\left(\omega_{d}, F o_{\mathrm{d}}\right)}{\left[1-\varphi_{0}\left(\omega_{d}, F o_{\mathrm{d}}\right)\right]^{2}} \\
\Phi\left[\varphi_{0}\left(0, F o_{\mathrm{d}}\right)\right]=\left(1-\frac{1}{B i_{\mathrm{d}}}\right) \cdot \frac{1}{3} \cdot \\
\cdot \ln \left[1-\varphi_{0}^{3}\left(0, F o_{\mathrm{d}}\right)\right]-\frac{1}{\sqrt{3}} \cdot \operatorname{arctg} \frac{2 \cdot \varphi_{0}\left(0, F o_{\mathrm{d}}\right)+1}{\sqrt{3}}+
\end{gathered}
$$




$$
+\frac{1}{6} \cdot \ln \frac{1+\varphi_{0} \cdot\left(0, F o_{\mathrm{d}}\right)+\varphi_{0}^{2}\left(0, F o_{\mathrm{d}}\right)}{\left[1-\varphi_{0}\left(0, F o_{\mathrm{d}}\right)\right]^{2}}
$$

The received values are used for determination of heat agent moisture content. The interconnection between values $\varphi_{0}$ and $x$ is calculated by the dependence:

$$
\frac{x_{1}-x_{n}}{x_{\text {нас }}-\mathrm{x}_{\mathrm{n}}}=\frac{\varphi_{0}^{3}\left(\omega_{\partial}, F o_{\mathrm{d}}\right)-\varphi_{0}^{3}\left(0, F o_{\mathrm{d}}\right)}{1-\varphi_{0}^{3}\left(0, F o_{\mathrm{d}}\right)}
$$

After reaching the equilibrium moisture content by the upper layer of particles the zone which separates the dried material and the material which is under drying condition, moves down. At definite time $F o_{\mathrm{d}}>F o_{0 \mathrm{~d}}$ the length of dried layer is equal to $\omega_{d 0}$. The equation system (9)-(11) with limiting conditions on the separating zone of dry and moist material has to be solved.

$$
\begin{gathered}
x_{1}\left(\omega_{d 0}, F o_{\mathrm{d}}\right)=x_{n} \\
\varphi_{0}\left(\omega_{d 0}, F o_{\mathrm{d}}\right)=0
\end{gathered}
$$

The differential Eq. (22) depends on integrating with new limiting conditions

$$
\int_{0}^{\varphi_{0}\left(\omega_{d}, F_{o_{d}}\right)} \frac{\varphi_{0}^{2} \cdot\left(\frac{1}{B i_{d}}-1\right)+\varphi_{0}}{\left(1-\varphi_{0}^{3}\right)} d \varphi_{0}=\int_{\omega_{d 0}}^{\omega_{d}} d \omega_{d}
$$

The solution of Eq. (29) can be represented as follows:

$$
\Phi\left[\varphi_{0}\left(\omega_{d}, F o_{\mathrm{d}}\right)-\Phi(0)\right]=\omega_{d}-\omega_{d 0}
$$

The value $\varphi_{0}\left(\omega_{d}, F o_{d}\right)$ is calculated by dependence (26), and $F(0)$ is calculated by (27).

The moisture content value of the heat agent $x_{1}$ for the second zone will be calculated as follows:

$$
\frac{x_{1}-x_{n}}{x_{s a t}-x_{\mathrm{n}}}=\frac{\varphi_{0}^{3}\left(\omega_{d}, F o_{\mathrm{d}}\right)-\varphi_{0}^{3}\left(\omega_{d 0}, F o_{\mathrm{d}}\right)}{1-\varphi_{0}^{3}\left(\omega_{d 0}, F o_{\mathrm{d}}\right)}=\varphi_{0}^{3}\left(\omega_{d}, F o_{d}\right)
$$

\subsubsection{The determination of movement zone velocity of dried material}

Let us make differentiation of Eq. (22) according to $\partial F o_{\mathrm{d}}$ and represent it as follows:

$\varphi_{0} \cdot\left[\frac{\varphi_{0}}{B i_{\mathrm{d}}}+\left(1-\varphi_{0}\right)\right] \cdot \frac{\partial \varphi_{0}}{F o_{\mathrm{d}}}=-\left(1-\varphi_{0}^{3}\right) \cdot \frac{\partial \omega_{d 0}}{\partial F o_{\mathrm{d}}}$ where $\frac{\partial \omega_{d 0}}{F o_{\mathrm{d}}}$ - is the movement velocity of separation zone boundary of dry and moist material.

We calculate from Eq. (15) the left part of equation and by substitution this value in Eq. (32) we get the equation:

$$
\frac{x_{1}-x_{s a t}}{\Delta \rho}=\left(1-\varphi_{0}^{3}\right) \cdot \frac{\partial \omega_{d 0}}{\partial F o_{d}}
$$

For value $\varphi_{0}=0$ (boundary separation of zones) $\mathrm{x}_{1}=x_{n}$, and transport velocity of the zone is:

$$
\frac{\partial \omega_{d 0}}{\partial F o_{\mathrm{d}}}=\frac{x_{s a t}-x_{n}}{\Delta \rho}
$$

In the common case the bond between moisture content of the heat agent $x, \partial F o_{\mathrm{d}}$ time and dimensionless layer length $\omega_{\partial}$ will be calculated by:

$$
\omega_{d}-\omega_{d 0}=\frac{x_{s a t}-x_{1}}{\Delta \rho} \cdot\left(F o_{\mathrm{d}}-F o_{\mathrm{d} 0}\right)
$$

where $\mathrm{Fo}_{\mathrm{d} 0}-$ is achievement time of dry material zone $\omega_{d 0}$.

For adequacy control of above-mentioned model we use the data shown in Fig 1. It is seen that the time of achievement the equilibrium moisture by super phosphate layer with the height of $48 \mathrm{~mm}$ is $2060 \mathrm{~s}$.

The time of achievement the equilibrium moisture of the super phosphate upper layer calculated according to (18) was $\tau_{I}=1217 \mathrm{~s}$. The movement time of mass exchange zone to the perforated partition calculated from Eq. (34) is $\tau_{I I}=678 s$, then the total theoretically calculated drying time of granulated super phosphate by filtration method is:

$$
\tau=1217+678=1895 s,
$$

and the relative error of theoretically calculated time will be:

$$
\Delta=\left|\frac{1895-2060}{1895}\right| \cdot 100 \approx 8,7 \% .
$$

The analogical calculations carried out for amophose have shown that the relative error is $11.3 \%$ thus it is accepted for project efficiency calculations in the filtration drying process. 


\section{Conclusions}

1. The differential equation system in dimensionless parameters which describes the heat exchange in the second period of drying during filtration drying of granulated mineral fertilizers is proposed and substantiated.

2. The received calculation dependences enable to calculate the moisture content of the heat agent in the second period of filtration drying of dispersion materials.

3 . The received calculation dependence enables to determine the transport velocity of the zone of the dried material during filtration drying in the second period.

4. The adequacy of the proposed method for description of temperature fields of the heat agent in the second period of filtration drying of dispersion materials is determined.

\section{References}

[1] Atamanyuk V.: Khimichna Promyslovist Ukrainy, 2007, 4, 24.

[2] Khanyk Ya., Gumnytskyi Ya., Atamanyuk V. and Bileyi P.: Naukovyi visnyk: Problemu derevoobrobnogo vyrobnytstva. Zbirnyk prac, 1994, 2, 29.

[3] Kochetkov V.: Granulirovanie mineralnykh udobrenyi. Khimiya, Moskwa 1975.

[4] Posyn M.: Tekhnologiya mineralnykh udobrenyi. Khimiya, Leningrad 1983.
[5] Lykov A.: Teoriya sushky. Energiya, Moskwa 1968.

[6] Atamanyuk V.: Mezhdunarodnayaj nauchnoprakticheskaya konferentsya "Povyshenie energeticheskoi efektyvnosti pishvykh i khimicheskikh proisvodstv". Odessa 2007, 203.

[7] Romankov P. and Frolov V.: Massoobmennie prosessy khimicheskoi tekhnologii (sistemy s dispersnoj tverdoi fazoj). Khimiya, Leningrad 1990.

[8] Akselrud G.: Massoobmen v sisteme tverdoe telozhydkost. Izd-vo Lvovskogo universiteta, Lviv 1970.

[9] Dvait G.: Tablitsy integralov i drugie matematicheskie formuly. Nauka, Moskwa 1977.

\section{ДИНАМІКА МАСООБМІНУ ПІД ЧАС ДРУГОГО ПЕРІОДУ ФІЛЬТРАЦЙНОГО ВИСУШУВАННЯ}

Анотація. Стаття присвячена експериментальним $i$ теоретичним дослідженням кінетики $i$ динаміки фільтраційного висушування дисперсних капілярно-пористих матеріалів, зокрема, мінеральних гранульованих добрив. Запропонована фізична модель вологої частинки та система диферениійних рівнянь, щуо описує тепломасообмін у другому періоді висушування $і$ дає змогу визначити швидкість переміщення зони масообміну в шарі дисперсного матеріалу під час фільтраційного висущування.

Ключові слова: кінетика, динаміка, фільтраційне висушування, дисперсний матеріал, мінеральні добрива, другий період, математична модель, фізична модель. 